\title{
General considerations on the future of nutrition and its social aspects
}

\author{
By A. Neuberger, Lister Institute of Preventative Medicine, Chelsea Bridge \\ Road, London
}

The discussion which has taken place today has shown clearly that nutrition, as an academic discipline, covers a very wide field. It is part of the general problem as to the way our environment affects the health of human beings, or in the case of agriculture, the health and performance of animals, which are of economic interest to man. We are therefore concerned with the interplay of the diet in its wildest sense with both genetic and other environmental factors, and in assessing the importance of the diet we have to give consideration to other aspects which will influence the performance of human beings or, for instance, of dairy cattle. A good example might be provided by the problem of the effect of diet on cardiovascular disease. It would be wrong in this case to leave out of consideration genetic factors, physiological stress, and environmental factors other than diet. Similar considerations must obviously apply to the whole field of the aetiology of disease. This opens the whole question of the extent to which research workers in nutrition should be involved in either fundamental research on the one hand, and the application of nutrition, that is, the social, economic and physiological problems which arise when nutritional principles have to be applied to particular situations. It can be argued that nutrition research should encompass a very large part of the study of metabolism. It seems to me quite reasonable to suggest that the study of protein metabolism in the whole organism and its regulation is a legitimate activity of the nutritional scientist. On the other hand, the detailed mechanism of protein synthesis at the ribosomal or sub-cellular level is an activity which is more properly carried out by the pure biochemist. The nutrition worker must of course be active in the field of protein metabolism, and must be aware of the work going on in the sub-cellular level in order to interpret his own experiments in a reasonable manner. Similar considerations would apply to other fields, such as carbohydrate and lipid metabolism. Similar questions arise, however, when we want to study the effect of diet on cardiovascular disease. The pathology of this group of diseases is obviously the work of the pathologist, but the nutrition worker in this specialist field of research must be fully aware of the advances made by other scientists. At the other end of the spectrum, I am sure that the research worker in nutrition cannot dissociate himself from sociological, economic and anthropological considerations, which must necessarily enter into discussion of the application of nutritional science to human populations.

Nutrition is perhaps now in the position where it has common boundaries with many intellectual activities in our society, and the real danger exists that it may become so highly diversified that it will lack real focus or a sound basis. This, I feel, is one of the major problems which we should discuss.

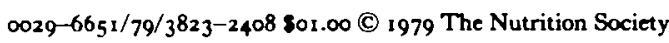


Nutrition has now become a matter of considerable practical importance. It may affect the balance and distribution of our agricultural production, and it may influence national policy in a variety of other ways. We are required to give guidance and advice on matters either where the evidence is incomplete, or where a consensus of scientific information is lacking. There are many prominent workers in nutrition who, for instance, feel that we have sufficient information to give definite advice leading to a reorientation of agricultural production. The opinion is held in many quarters that we should greatly reduce the intake of dairy products by human populations. Such scientists admit that the evidence may not be completely satisfactory, but is sufficiently strong for action to be taken. Others are doubtful and believe that such action, particularly in the form of legislation or government regulation, cannot be taken unless evidence were quite convincing. This is an important problem for the whole relationship of science to society, and is not exclusive to nutrition research. It arises in other fields, such as the proliferation of nuclear reactors, the problems associated with the environmental hazards, and many other fields of human activity. Economists are familiar with this kind of problem, and governments have in the past taken the advice of those economists who are generally in agreement with their own political thinking. Scientists have not until recently been prepared to give advice unless an almost full consensus of the scientific community was obtained, or unless the evidence on which their advice was based amounted to virtual certainty. This is another of the major problems which nutritionists now have to face. 